\title{
Correlation between Iron Parameters and Platelet Parameters in Iron Deficiency Anemia
}

\author{
Sanat Chalise', Nishant Acharya' ${ }^{2}$, Sailesh B Pradhan' \\ 'Department of Pathology, Kathmandu Medical College, Sinamangal, Kathmandu Nepal, 'Department of \\ Medicine, Kathmandu Medical College, Sinamangal, Kathmandu, Nepal
}

\section{Corresponding author:}

Sanat Chalise, MBBS, MD

Department of Pathology, Kathmandu Medical College Public Limited, Sinamangal, Kathmandu, Nepal. Email: chalisesanat@gmail.com

Submitted : September 6, 2019

Accepted : November 29, 2019

\begin{abstract}
Introduction

Iron deficiency anemia is the most common type of anemia and is diagnosed by iron studies. Reactive thrombocytosis is usually seen in iron deficiency anemia. The objectives of the study is to correlate between iron parameters and platelet parameters in patient with iron deficiency anemia.
\end{abstract}

\section{Methods}

This was a cross-sectional study done in Department of Pathology at Kathmandu Medical College, Sinamangal between December 2018 to May 2019. Blood samples of 81 iron deficiency anemia patients were analysed to determine iron parameters and platelet parameters. SPSS version 20 was used to analyse the data.

\section{Results}

Thrombocytosis was seen in 62 (76.5\%) patient with iron deficiency anemia. Platelet count was negatively correlated with serum iron, percentage saturation and platelet distribution width $(p<0.001$, for all) while positive correlation was obtained between platelet count and plateletcrit $(p<0.05)$. Plateletcrit showed negative correlation with serum iron $(p<0.001)$ and platelet distribution width $(p<0.05)$ while positive correlation was obtained with mean platelet volume, total iron binding capacity and platelet $(p<0.05$, for all). There was negative correlation between mean platelet volume and platelet count $(p<0.001)$. Positive correlation was obtained between mean platelet volume and plateletcrit $(p<0.05)$. Correlation was not found between mean platelet volume and iron parameters $(p>0.05)$. Platelet distribution width showed negative correlation with total iron binding capacity, platelet $(p<0.001$, for both), plateletcrit $(p<0.05)$.

\section{Conclusion}

Thrombocytosis is more commonly observed as compared to thrombocytopenia in patient with iron deficiency anemia. Serum iron and percentage saturation are the most important parameters affecting the platelet count.

Keywords: Iron deficiency anemia, platelet parameters, thrombocytosis

\section{INTRODUCTION}

A nemia is defined by World Health Organization $(\mathrm{WHO})$ as hemoglobin $(\mathrm{Hb})$ level $<12.0 \mathrm{gm} / \mathrm{dl}$ in women and $<13.0 \mathrm{gm} /$ $\mathrm{dl}$ in men. ${ }^{1}$ Iron deficiency anemia (IDA) is the most common type of anemia worldwide and is estimated to be the cause of $50 \%$ of anemic cases. ${ }^{2}$ IDA is commonly diagnosed by change in iron studies. ${ }^{3}$

Platelet parameters usually altered in reactive mechanism and neoplastic overproduction. ${ }^{4}$ Infections, acute bleeding and IDA causes reactive thrombocytosis. IDA is a common cause of reactive thrombocytosis the exact mechanism of which is unknown. ${ }^{5}$ 
Previous studies suggested that platelet parameter change in IDA is because of morphological features of platelet. 6,7 The aim of the study is to evaluate the relation between iron parameters and platelet parameters in IDA patients.

\section{METHODS}

This was a cross-sectional study conducted among patient visiting Kathmandu Medical College Public Limited, Sinamangal, Nepal from December 2018 to May 2019. The ethical approval for the study was taken from Institutional Review Committe of Kathmandu Medical College Teaching Hospital, Sinamangal. The written informed consent was obtained from each participants. The inclusion criteria includes: hemoglobin less than $12 \mathrm{gm} / \mathrm{dl}$ in women and $13 \mathrm{gm} / \mathrm{dl}$ in men. Serum ferritin less than $6 \mu \mathrm{g} / \mathrm{l}$ and transferrin saturation (Tfsat) less than $13 \%$. These reference values are used in the pathology lab of Kathmandu medical college public limited. The patient with other causes of reactive thrombocytosis (acute hemorrhage, infection, malignancy and chronic inflammatory disease) were excluded from the study.

Fresh blood with ethylene diamine tetraacetic acid (EDTA) was analyzed to determine red blood cell and platelet parameters between 1 to 3 hours after sampling using Nihon Kohden coulter model number MEK-6410K. Blood sample for serum iron parameters including serum iron, Total iron binding capacity (TIBC), Tfsat and ferritin were

Table 1. Hematological parameters in patients with iron deficiency anemia

\begin{tabular}{|c|c|c|}
\hline Variables & Mean $\pm S D$ & $\begin{array}{c}\text { Normal } \\
\text { value }\end{array}$ \\
\hline $\begin{array}{l}\text { Red blood cell parameters } \\
\text { Hemoglobin }(\mathrm{gm} / \mathrm{dl}) \\
\text { Hematocrit }(\%) \\
\mathrm{MCV}(\mathrm{fl}) \\
\mathrm{MCH}(\mathrm{pg}) \\
\mathrm{MCHC}(\mathrm{gm} / \mathrm{dl}) \\
\operatorname{RDW}(\%)\end{array}$ & $\begin{array}{l}7.4 \pm 1.3 \\
23 \pm 5.1 \\
67.1 \pm 5.1 \\
20.6 \pm 2.8 \\
27.3 \pm 2.3 \\
20.2 \pm 2.1\end{array}$ & $\begin{array}{c}12-16 \\
36-45 \\
80-100 \\
27-33 \\
33-37 \\
11-14\end{array}$ \\
\hline $\begin{array}{l}\text { Platelet parameters } \\
\text { Platelet }(\times 103 / \mu \mathrm{L}) \\
\text { MPV (fI) } \\
\text { PCT }(\%) \\
\text { PDW (\%) }\end{array}$ & $\begin{array}{c}455.6 \pm 139 \\
8.3 \pm 0.9 \\
0.3 \pm 0.06 \\
44.1 \pm 4.9\end{array}$ & $\begin{array}{c}150-450 \\
9-13 \\
- \\
-\end{array}$ \\
\hline $\begin{array}{l}\text { Iron parameters } \\
\text { Serum iron }(\mu \mathrm{g} / \mathrm{dl}) \\
\text { TIBC }(\mu \mathrm{g} / \mathrm{dl}) \\
\text { Percentage saturation } \\
(\%) \\
\text { Ferritin }(\mu \mathrm{g} / \mathrm{l})\end{array}$ & $\begin{array}{c}30.1 \pm 3.5 \\
511.4 \pm 47.2 \\
\\
6.1 \pm 2.07 \\
4.5 \pm 0.99\end{array}$ & $\begin{array}{c}60-150 \\
250-450 \\
\\
18-45 \\
15-70\end{array}$ \\
\hline
\end{tabular}

collected in tubes without anticoagulant and were analyzed after four hours using Maglumi Chemiluminescence Analyzer.

The data was analyzed using SPSS Statistics version 20.0. The values was shown as mean \pm standard deviation. The correlation of platelet parameters which includes platelet count, plateletcrit (PCT), mean platelet volume (MPV) and platelet distribution width (PDW) with iron parameters were analyzed by Pearson's correlation. P value $<0.05$ was considered as statistically significant.

\section{RESULTS}

Among 81 patient enrolled in this study, 17 (20.9\%) were male and 64 (79.01\%) were female. The mean age was 45.46 year. The mean $\mathrm{Hb}$ level was 7.4 $\mathrm{gm} / \mathrm{dl}$. In patients with IDA, thrombocytosis was seen in $62(76.5 \%)$ patient and thrombocytopenia was seen in $3(3.7 \%)$ patient. Sixteen (19.75\%) patient had normal platelet count. Hematological data of patient are shown in table 1. Pearson's correlation between platelet parameters and iron parameters as well as between platelet parameters are shown in table 2 and 3.

Platelet count showed negative correlation with serum iron, Tfsat, PDW ( $p<0.001$, for all), MPV $(p<0.05)$ while positive correlation was obtained between platelet count and PCT $(p<0.05)$.

PCT showed negative correlation with serum iron $(p<0.001)$ and PDW $(p<0.05)$ whereas positive correlation was obtained with MPV, TIBC, platelet $(p<0.05$, for all).

Table 2. Correlation between platelet parameters and iron parameters

\begin{tabular}{lcccc}
\hline $\begin{array}{c}\text { Para- } \\
\text { meter }\end{array}$ & Platelet & PCT & MPV & PDW \\
\hline $\begin{array}{l}\text { Serum } \\
\text { iron }\end{array}$ & & & & \\
$\quad r$ & -0.05 & -0.0009 & 0.1519 & 0.07 \\
p value & $<0.001$ & $<0.001$ & 0.214 & 0.367 \\
Serum & & & & \\
ferritin & & & & \\
$\quad r$ & 0.07 & 0.108 & 0.0178 & -0.059 \\
p value & 0.196 & 0.450 & 0.289 & 0.698 \\
TIBC & & & & \\
$r$ & 0.199 & 0.15 & 0.0169 & -0.309 \\
p value & 0.665 & 0.012 & 0.965 & $<0.001$ \\
Tfsat & & & & \\
$r$ & -0.11 & -0.161 & 0.078 & 0.147 \\
p value & $<0.001$ & 0.734 & 0.864 & 0.112 \\
\hline
\end{tabular}

$r=$ correlation coefficient 
Table 3. Correlation between platelet parameters

\begin{tabular}{lcccc}
\hline Parameter & Platelet & PCT & MPV & PDW \\
\hline Platelet & & & & \\
r & - & 0.265 & -0.144 & -0.298 \\
p value & & 0.023 & 0.012 & $<0.001$ \\
PCT & & & & \\
r & 0.265 & - & 0.029 & -0.281 \\
p value & 0.023 & & 0.043 & 0.039 \\
MPV & & & & \\
r & -0.144 & 0.029 & - & -0.198 \\
p value & 0.012 & 0.043 & & 0.346 \\
PDW & & & & \\
r & -0.298 & -0.281 & -0.198 & - \\
p value & $<0.001$ & 0.039 & 0.346 & \\
\hline
\end{tabular}

$\mathrm{r}=$ correlation coefficient

There was negative correlation between MPV and platelet count $(p<0.001)$ where as positive correlation was obtained between MPV and PCT $(p<0.05)$. Correlation was not found between MPV and Iron parameters.

PDW showed negative correlation with TIBC, platelet ( $p<0.001$ for both), PCT $(p<0.05)$.

\section{DISCUSSION}

Our study showed IDA was common in female 64 (79.01\%). Similar results were obtained by Alalimi et $\mathrm{al}^{7}$ and Mishra et $\mathrm{al}^{8}$ in their study and they concluded that inadequate intake of dietary iron, inadequate intake of dietary micronutrients, lack of awareness of iron deficiency, excessive menstrual loss, pregnancy and nutritional status were the possible cause.

The relationship between IDA and thrombocytosis remains unclear howevervarious studies suggested that iron deficiency causes megakaryocytic expansion and stimulates megakaryocytic differentiation, independently from thrombopoietin (TPO), interleukin-6 and interleukin-11. ${ }^{9}$ Bilic and Bilic in their study explained that homology between the aminoacid sequence between TPO and erythropoietin (EPO) results in thrombocytosis in children with IDA. ${ }^{10}$ Some studies have also reported that thrombocytopenia is seen in severe IDA because of high EPO response. ${ }^{11}$ In the present study thrombocytosis was seen in 62 (76.5\%) patient while thrombocytopenia was seen in $3(3.7 \%)$ patient. Findings of the present study show similar result to that of Kadikoylu et al ${ }^{12}$ and Kuku et al ${ }^{13}$.

Our study showed platelet count negatively correlated with serum iron, Tfsat, PDW, MPV. There was positive correlation between platelet and PCT. The result coincides with the result of Park et $\mathrm{al}^{6}$,
Kadikoylu et al' ${ }^{12}$, Kuku et $\mathrm{al}^{13}$ and Han et $\mathrm{al}^{14}$. Serum ferritin measurement is one of the most accurate diagnostic test for IDA. ${ }^{6}$ In the current study, no correlation was obtained between serum ferritin and platelets. Kuku et $\mathrm{al}^{13}$ also found no correlation between serum ferritin and platelet in their study but contradict to the result of our study, Kadikoylu et a ${ }^{12}$ found significant correlation between serum ferritin and platelets.

Special interest was shown in the literature between platelet count and MPV. In the current study there was negative correlation between MPV and platelet count where as positive correlation was obtained between Platelet crit and MPV. Similar findings were obtained in the study done by Levin and Bessman and Giles C and explained that the possible is due to decrease in maturation time of platelet and increase in polypoidy of megakaryocytes as the youngest platelet have largest size. ${ }^{15,16}$

There are few limitations in our study as comparision of parameters in non anemic patient were not done and also re-evaluation of statistically significant parameters were not done after the end of treatment. Furthermore we didn't assess thromboembolic events in our patient.

\section{CONCLUSION}

Thrombocytosis is most commonly observed as compared to thrombocytopenia in patient with iron deficiency anemia. Serum iron and percentage saturation are the most important parameters affecting the platelet count.

\section{ACKNOWLEDGEMENTS}

The authors would like to thank Pathology residents and laboratory staff of Kathmandu Medical College for cooperation to conduct the study. We would like to acknowledge all the participants for their sincere contribution to the study.

\section{CONFLICT OF INTEREST}

None declared.

\section{REFERENCES}

1. Cappellini MD, Motta I. Anemia in Clinical PracticeDefinition and Classification: Does Hemoglobin Change With Aging? Semin Hematol. 2015 Oct;52(4):261-9.

2. Liu K, Kaffes AJ. Iron deficiency anaemia: a review of diagnosis, investigation and management. Eur J Gastroenterol Hepatol. 2012 Feb;24(2):109-16.

3. Johnson-Wimbley TD, Graham DY. Diagnosis and management of iron deficiency anemia in the 21st century. Ther Adv Gastroenterol. 2011 
May;4(3):177-84.

4. Dan K. Thrombocytosis in iron deficiency anemia. Intern Med Tokyo Jpn. 2005 Oct;44(10):1025-6.

5. Evstatiev R, Bukaty A, Jimenez K, Kulnigg-Dabsch $S$, Surman L, Schmid W, et al. Iron deficiency alters megakaryopoiesis and platelet phenotype independent of thrombopoietin. Am J Hematol. 2014 Apr 12;89(5):524-9.

6. Park M-J, Park P-W, Seo Y-H, Kim K-H, Park S-H, Jeong $\mathrm{J}-\mathrm{H}$, et al. The relationship between iron parameters and platelet parameters in women with iron deficiency anemia and thrombocytosis. Platelets. 2013;24(5):348-51.

7. Al-alimi AA, Bashanfer S, Morish MA. Prevalence of Iron Deficiency Anemia among University Students in Hodeida Province, Yemen. Anemia. 2018;2018:1-7.

8. Mishra SK, Marasini S, Gupta BK, Agrawal KK, Gautam N. Prevalence of Iron Deficiency Anemia in Anemic Patients: A Hospital Based Study. J Univers Coll Med Sci. 2018 Dec 3;6(2):41-5.

9. Holbro A, Volken T, Buser A, Sigle JP, Halter $J P$, Passweg JR, et al. Iron deficiency and thrombocytosis. Vox Sang. 2017 Jan;112(1):87-92.

10. Bilic E, Bilic E. Amino Acid Sequence Homology of Thrombopoietin and Erythropoietin May
Explain Thrombocytosis in Children With Iron Deficiency Anemia. J Pediatr Hematol Oncol. 2003 Aug;25(8):675

11. Stohlawetz PJ, Dzirlo L, Hergovich N, Lackner E, Mensik C, Eichler HG, et al. Effects of erythropoietin on platelet reactivity and thrombopoiesis in humans. Blood. 2000 May 1;95(9):2983-9.

12. Kadikoylu G, Yavasoglu I, Bolaman Z, Senturk T. Platelet parameters in women with iron deficiency anemia. J Natl Med Assoc. 2006 Mar;98(3):398402.

13. Kuku I, Kaya E, Yologlu S, Gokdeniz R, Baydin A. Platelet counts in adults with iron deficiency anemia. Platelets. 2009 Sep;20(6):401-5.

14. Han D-D, Ma C, Zhao L, Gao Y-J, Su Y-H. [Relationship between Iron Metabolism and Platelet Parameters in Patients with Iron Deficiency Anemia]. Zhongguo Shi Yan Xue Ye Xue Za Zhi. 2018 Dec;26(6):1738-41.

15. Levin J, Bessman JD. The inverse relation between platelet volume and platelet number. Abnormalities in hematologic disease and evidence that platelet size does not correlate with platelet age. J Lab Clin Med. 1983 Feb;101(2):295-307.

16. Giles C. The platelet count and mean platelet volume. Br J Haematol. 1981 May;48(1):31-7. 